\title{
Erratum to "Regardless of the Puncture Angle, a Tuohy Needle with Sand-Blasted Steel at the Tip of the Bevel Is a Valid Needle on the Ultrasonic Images", [Open Journal of Anesthesiology, 2016, 6, 101-104]
}

\author{
Ichikawa Yuki ${ }^{1}$, Hironobu Ueshima ${ }^{2 *}$, Akira Kitamura1 \\ ${ }^{1}$ Department of Anesthesiology, Saitama Medical University International Medical Center, Saitama, Japan \\ ${ }^{2}$ Department of Anesthesiology, Showa University Hospital, Tokyo, Japan \\ Email: *ueshimhi@yahoo.co.jp
}

How to cite this paper: Yuki, I., Ueshima, H. and Kitamura, A. (2021) Erratum to "Regardless of the Puncture Angle, a Tuohy Needle with Sand-Blasted Steel at the Tip of the Bevel Is a Valid Needle on the Ultrasonic Images", [Open Journal of Anesthesiology, 2016, 6, 101-104]. Open Journal of Anesthesiology, 11, 219-220.

https://doi.org/10.4236/ojanes.2021.117021

Received: June 27, 2021

Accepted: July 16, 2021

Published: July 19, 2021

Copyright (อ 2021 by author(s) and Scientific Research Publishing Inc. This work is licensed under the Creative Commons Attribution International License (CC BY 4.0).

http://creativecommons.org/licenses/by/4.0/

\begin{abstract}
The original online version of this article (Ichikawa Yuki, Ueshima Hironobu, Hiroshi Otake, Akira Kitamura (2016) Regardless of the Puncture Angle, a Tuohy Needle with Sand-Blasted Steel at the Tip of the Bevel Is a Valid Needle on the Ultrasonic Images, 2016, 6, 101-104,

https://file.scirp.org/Html/1-1920418_68780.htm) unfortunately contains some mistakes. The authors wish to correct the errors in co-authors, Table 1, and Table 2.
\end{abstract}

Our article had some mistakes in co-authors, Table 1, and Table 2.

The followings are the list of errata and correct tables

List of Errata

\begin{tabular}{ccc}
\hline & TRUE & FALSE \\
\hline \multirow{2}{*}{ P.101 Co-Authors } & Yuki Ichikawa, Hironobu Ueshima, & Yuki Ichikawa, Hironobu Ueshima, \\
& Akira Kitamura & Hiroshi Otake, Akira Kitamura \\
\hline
\end{tabular}

Table 1

\begin{tabular}{ccccc}
\hline \multicolumn{5}{c}{ the depth from Blue Phantom $(\mathrm{cm})$} \\
\hline Rafa & 0.5 & 1.0 & 1.5 & 2.0 \\
\hline Non-coated & $193.7(6.5)$ & $183.3(6.0)$ & $189.3(9.1)$ & $182.1(5.7)$ \\
& $133.8(3.8)$ & $116.9(8.2)$ & $94.2(4.2)$ & $67.3(1.5)$ \\
\hline
\end{tabular}


Table 2

\begin{tabular}{ccccccc}
\hline \multicolumn{7}{c}{ the depth from Blue Phantom $(\mathrm{cm})$} \\
\hline \multirow{2}{*}{0.5} & 1.0 & 1.5 & 2.0 & 2.5 & 3.0 \\
\hline Rafa & $194.0(7.3)$ & $188.3(5.7)$ & $187.2(4.9)$ & $179.4(4.9)$ & $172.0(4.5)$ & $163.8(7.5)$ \\
Non-coated & $134.4(2.7)$ & $111.6(7.3)$ & $104.5(5.8)$ & $86.1(7.2)$ & $72.2(3.9)$ & $56.6(4.6)$ \\
\hline
\end{tabular}

